\title{
Verbal satiation and free recall '
}

DENNIS M. ROBERTS AND F. J. KING, FLORIDA STATE UNIVERSITY

IAN REID, UNIVERSITY OF HAWAII

Twenty Ss were satiated on a word that was either related or not related to a list of eight nouns. After satiation, the list of eight nouns was presented, followed by immediate recall. Another 20 Ss saw the list first followed by satiation and recall. Satiation time was either 15 or $30 \mathrm{sec}$. The satiaeffect was found to be significant in the retroactive condition.

The topic of verbal satiation (VS) has received considerable attention in recent years. Much of the research has been concermed with the connotative or associative aspects of meaning and has followed the work of Lambert \& Jakobovits (1960). Little work, however, has been reported relating VS to memory. If satiation reduces the connotative or associative meaning of a verbal unit, then interference in recall should be evidenced when a verbal mediator for a list of nouns is satiated. The present investigation represents an exploration into this area.

\section{Materials}

Experimental materials consisted of elght different descriptive adjectives. Accompanying each adjective was a list of eight nouns that were common associates to the descriptive adjective. A list consisted of four high and four low dominance level words alternated on a L-H-L-H basis. Words were taken from Underwood \& Richardson's (1956) lists of sense impression descriptive adjectives which are commonly associated with groups of nouns. A sample list used in the present study was: rice, flea, atom, closet, pin, minnow, pollen, and crumb-with an assoclated descriptive adjective "small." Seven similar lists were utilized.

Words were individually printed on transparencies and shown by a slide projector. Each $S$ was given a mimeographed sheet of paper on which to write recall words corresponding to the eight lists. A stopwatch was used to time the particular words that were to be satiated.

\section{Precedure}

Each $S$ was tested individually. The $E$ read the directions which varied slightly depending on whether the Ss were in the proactive or retroactive group. Two practice trials were given and each $\mathbf{S}$ was corrected if necessary.

When an $S$ in the proactive group was ready for the test trials, the $E$ projected the first satiation word on the screen. The $S$ then repeated this word out loud as fast as he could for a specified time. The slide remained in view during the satiation period. After repetition was completed, the eight nouns of the list were projected, one word at a time, onto the screen and the $S$ said each word aloud. A blank frame appeared after the eighth word at which time the
$S$ wrote down all the nouns he could remember from that list. The recall interval was approximately 30 sec. This procedure was continued for seven additional lists. In the retroactive group the procedure was essentially the same except that the satiation of single words was interpolated between the presentation of the list and the recall period.

There were two satiation (single word repetition) conditions. The Satiate-Related (S-R) condition called for $S$ to repeat a descriptive adjective which was a common associate with all the nouns in the list. The Satiate-Nonrelated (S-NR) condition called for repetition of a word unrelated to the memory list. Two repetition time intervals were used-15 and 30 sec. A 2 by 2 by 2 by 20 analysis of variance factorial design was used. The factors were the two satiation conditions, the two time intervals, the two dominance levels, and the $20 \mathrm{Ss}$ since all So recelved all treatment and time conditions. To control for possible PI effects, two orders of list presentation were used. Half of the Ss in each design condition were tested under each order. All Ss satiated on the same related or non-related descriptive adjectives. Order of presentation of words within lists was held constant for all Ss.

\section{Subjects}

Forty undergraduate female Ss were taken from education courses at Florida State University. Both the proactive and retroactive conditions were assigned $20 \mathrm{Ss}$ each.

\section{Results and Discussion}

In the proactive desigm, analysis of variance showed no significant difference between either the satiation ( $F<1, \mathrm{df}=1 / 19, \mathrm{~ns})$ or time $(\mathrm{F}=1.05, \mathrm{df}=1 / 19$, ns) conditions. Also, no significant interaction was found. The mean scores for the time and satiation variables are presented in Table 1 . In the retroactive design a significant difference was found between the $S-R$ and $S-N R$ conditions $(F=7.42$, df $=1 / 19$, $p<.05)$ with better recall being achleved when Ss satiated on words that were not related to the list of eight nouns. No significant difference $(F<1)$ was found between the two satiation times. No significant

Table 1. Mean Scores for the Time and Satiation Variables in the Proactive Desien*

\begin{tabular}{ccc} 
Conditions & S-R & S-NR \\
\hline 15 sec & 6.05 & 5.93 \\
30 sec & 6.05 & 6.33 \\
Total & 6.05 & 6.13 \\
\hline
\end{tabular}

- Score represents average of two repeated measurements. 
Table 2. Mean Scores for the Time and Satiation Variables in the Proactive Design*

\begin{tabular}{lll} 
Conditions & S-R & S-NR \\
\hline $15 \mathrm{sec}$ & 5.15 & 5.40 \\
$30 \mathrm{sec}$ & 5.10 & 5.55 \\
Total & 5.13 & 5.48 \\
\hline
\end{tabular}

* Score represents average of two repeated measurements.

interactions of treatment and dominance level were found in either analysis. Table 2 presents the mean scores for the time and satiation variables for the retroactive design.

Of three theoretical interpretations reviewed by Amster (1964)-a learning interference model, a cognitive reactive inhibition model and an adaptation level model-the learning interference explanation seems most relevant to the present investigation. The learning model suggests that repeating a word over and over again increases the probability of this response being continually repeated or thought of in a later test situation. Implicit in this interpretation is the possibility of an $S$ producing a large number of relevant associations to the word. From the above discussion, it can be reasoned that satiation on the term "small," which could be classified as a mediator for a list of small objects, would tend to increase the probabllity of "small" being covertly repeated or relevant associations to small being made. This means that an $\mathrm{S}$ who normally finds a mediator useful in recall might now find it to be interfering since the satiation treatment might cause it to produce similar stimuli to those in the noun list. This, in turn, might make the task of discriminating list words from non-list words more difficult.

Although these results seem compatible with the learning interference model, the fact that the satiation effect was found only in the retroactive condition and that length of the satiation interval did not produce differential effects deserves comment. If a satiation effect is a short lived phenomenon, then it might be expected that Ss would experience little interference when the satiation treatment came before the list was presented. In relation to the time variable, it is suggested that varied lengths of satiation result in little differential interference. Although the interference theory would predict the opposite, the present data does not support such a view.

\section{References}

Amster, Harriet. Semantic satiation and generation. Psychol. Bull. $1964,62,273-286$.

Lambert, W. E., \& Jakobovits, L. A. Verbal satiation and changes of meaning. J. exp. Psychol., 1960, 60, 376-383.

Underwood, B. J., \& Richardson, J. Some verbal materials for the study of concept formation. Psychol. Bull., 1956, 53, 84-95. Note

1. The computational work was made possible, in part, by a NSF Grant GP 671 to the Florida State University Computing Center. 